\title{
Passive Versus Active Circuit During Invasive Mechanical Ventilation in Subjects With Amyotrophic Lateral Sclerosis
}

\author{
Elisa De Mattia RPhysio, Elisa Falcier MD, Andrea Lizio MSc, Christian Lunetta MD, \\ Valeria A Sansone MD, Nicola Barbarito MD, Barbara Garabelli RPhysio, \\ Marino Iatomasi RPhysio, Elisabetta Roma MD, Fabrizio Rao MD, and Annalisa Carlucci MD
}

\begin{abstract}
BACKGROUND: Until recently, it has been considered essential to maintain the use of a doublelimb circuit in patients with amyotrophic lateral sclerosis (ALS) to avoid rebreathing expired air during invasive mechanical ventilation. Currently, life-sustaining home ventilators can work with a single, lighter circuit that is easier to manage. Our aim was to evaluate the effectiveness and safety of a single-limb circuit with intentional leaks (passive circuit) in comparison with a circuit with an expiratory valve (active circuit), in subjects with ALS who use invasive home ventilation. METHODS: We conducted a retrospective single-center study. The enrolled subjects were divided into 2 groups according to the type of exhalation port. The aim of the study was to compare arterial blood gases; nocturnal oxygen saturation recordings; and the occurrence of adverse events, both clinical and technical events. In addition, we compared the rate of mortality and unplanned hospital admissions that occurred within a year after discharge from the hospital. RESULTS: Forty-three subjects were included in our study: 23 who used a passive circuit and 20 who used an active circuit. No significant difference in nocturnal and diurnal gas exchanges was detected. The incidence of adverse events was significantly higher in the active circuit group (85\% in active circuit vs $30 \%$ in passive circuit, $P<.001)$. However, by splitting the adverse events into 2 categories, clinical and technical, the technical events were significantly more frequent in the active circuit group. None of these events led to hospital admission or death. CONCLUSIONS: The passive circuit was shown to be as effective and safe as the active circuit during home invasive ventilation in the subjects with amyotrophic lateral sclerosis. A future randomized controlled study is necessary to confirm these results and to extend indications to other pathologies. Key words: mechanical ventilation; chronic respiratory failure; tracheostomy; respiratory therapy; neuromuscular diseases; amyotrophic lateral sclerosis (ALS). [Respir Care 2018;63(9):1132-1138. @ 2018 Daedalus Enterprises]
\end{abstract}

\section{Introduction}

Amyotrophic lateral sclerosis (ALS) is a neurodegenerative disease that leads to the progressive loss of motor

\footnotetext{
Ms De Mattia, Dr Falcier, Ms Lizio, Dr Lunetta, Dr Sansone, Ms Garabelli, Mr Iatomasi, Mr Iatomasi, Dr Roma, and Dr Rao are affiliated with the NEuroMuscular Omnicentre, Fondazione Serena Onlus, Milan, Italy. Dr Sansone is affiliated with the Department of Biomedical Sciences for Health, Università degli Studi di Milano, Milan, Italy. Dr Barbarito is affiliated with the Respiratory Rehabilitation Care Unit, Fondazione Don Carlo Gnocchi, Istituto di Ricovero e Cura a Carattere Scientifico Santa Maria Nascente, Milan, Italy. Dr Carlucci is affiliated with the Pulmonary Rehabilitation Unit, Istituti Clinici Scientifici Maugeri, Istituto di Ricovero e Cura a Carattere Scientifico, Pavia, Italy.
}

neuron function and, ultimately, to death. Respiratory failure occurs in different stages of the disease, which usually represents the main cause of death. ${ }^{1}$ When continuous non-

\footnotetext{
Supplementary material related to this paper is available at http:// www.rcjournal.com.

The authors have disclosed no conflicts of interest.

Correspondence: Elisa De Mattia RPhysio, NEuroMuscularOmnicentre, Fondazione Serena Onlus, Niguarda Ca' Granda Hospital Piazza Ospedale Maggiore, 3, Milan, 20162 Italy. E-mail: elisa.demattia@ centrocliniconemo.it.
}

DOI: $10.4187 /$ respcare. 05866 


\section{Passive vs Active Circuit Ventilation in Subjects With AlS}

invasive ventilation is necessary $24 \mathrm{~h} /$ day or severe bulbar involvement occurs, tracheostomy and invasive mechanical ventilation should be considered. ${ }^{2}$ Invasive mechanical ventilation in patients with ALS is considered life sustaining; the patient's life depends on the mechanical ventilator functioning correctly. Since the 1980s, technological advances in the field of mechanical ventilation and the increasing use of noninvasive ventilation allowed the creation of more sophisticated ventilators that became increasingly more compact, portable, and easy to use, and with safety and performance profiles similar to ICU ventilators. At present, home ventilators can generally operate with a single-limb circuit, even in cases of invasive mechanical ventilation, which facilitates both the patient's management and mobilization.

According to the type of exhalation port, there are 2 types of single-limb circuits: an active circuit, with a true expiratory valve that directs all of the expired air out of the circuit; and a passive circuit, with a calibrated intentional leak placed proximal to the patient (Fig. 1). The passive circuit, with continuous flow into the circuit, was found to be as effective as the active circuit in avoiding rebreathing, even in cases of subjects who are hypercapnic and using noninvasive ventilation. ${ }^{3}$ Currently, several home mechanical ventilators have been cleared by the FDA and have received the European declaration of conformity to be used as life-sustaining devices during invasive mechanical ventilation, which can be applied with both circuits.

However, to our knowledge, no data on the safety of passive circuits during invasive mechanical ventilation are available in the literature; in particular, there are no studies that address the potential presence of rebreathing phenomena or efficacy of airway humidification, or the occurrence of technical problems. The aim of our study was to compare data obtained during a 1-y period about the safety and effectiveness of both active and passive circuits, in subjects with ALS and who, at home, were tracheostomized and using invasive ventilation with a single-limb circuit.

\section{Methods}

We conducted a retrospective single-center study from January 2012 to December 2014, which included patients with ALS referred to the NEuroMuscular Omnicentre Center in Milan. The study was approved by the Italian ethics committee Milan Area C (protocol 242-062016). We enrolled all patients who fit the following criteria: (1) a diagnosis of ALS, performed according to the El-Escorial revised and Awaji criteriaa-6; (2) treatment with invasive mechanical ventilation started in our center after a recent tracheostomy; (3) the need for mechanical ventilation for $>18 \mathrm{~h} / \mathrm{d}$; (4) use of a single-limb circuit;

\section{QUICK LOOK}

\section{Current knowledge}

Invasive mechanical ventilation is usually performed with a double-limb circuit. The majority of life-sustaining home ventilators can work with a single limb by using either an expiratory valve (active circuit) or a calibrated intentional leak (passive circuit). The passive circuit may expose patients to carbon dioxide rebreathing, or to ineffective airway humidification. However, both circuits can also be used in invasive ventilation.

\section{What this paper contributes to our knowledge}

The use of the passive circuit during invasive mechanical ventilation in the home in subjects with ALS was not inferior to the active circuit in providing adequate correction of respiratory gas exchange and in maintaining a similar profile of safety. Moreover, the passive circuit seemed to be related to a significantly lower number of technical problems.

(5) the prevalent use of closed ventilation through a cuffed tracheostomy tube; and (6) regular follow-up, at least once a year, performed according to the standards of our center.

The enrolled subjects were divided into the following 2 groups on the basis of the exhalation port used with each circuit: the passive circuit group and the active circuit group. The choice of the 2 types of exhalation ports was essentially driven by the following criteria. The subjects who were already using a "life support" ventilator for noninvasive ventilation at home were switched to invasive ventilation while maintaining the same ventilator and the same type of circuit. For the remaining subjects, the ventilator was chosen among those already available at home, preferably a passive circuit. For all the subjects, the pressure control mode, with or without target volume, was used. Optimal ventilation parameters were set by monitoring diurnal arterial blood gases and nocturnal oxygen saturation as well as according to the subject's tolerance.

Humidification during invasive ventilation was provided to all the subjects through a high-performance active humidifier (Model MR850, Fisher and Paykel Healthcare, Auckland, New Zealand). To enable the subjects to use a wheelchair, they received humidification with a heat and moisuture exchanger for a maximum of $4 \mathrm{~h} / \mathrm{d}$. All the subjects received ventilation through cuffed, non-fenestrated tracheostomy tubes with an inner cannula. All the subjects' caregivers participated in a theoretical and practical training protocol on the management of invasive ventilation at home. 


\section{Passive vs Active Circuit Ventilation in Subjects With AlS}
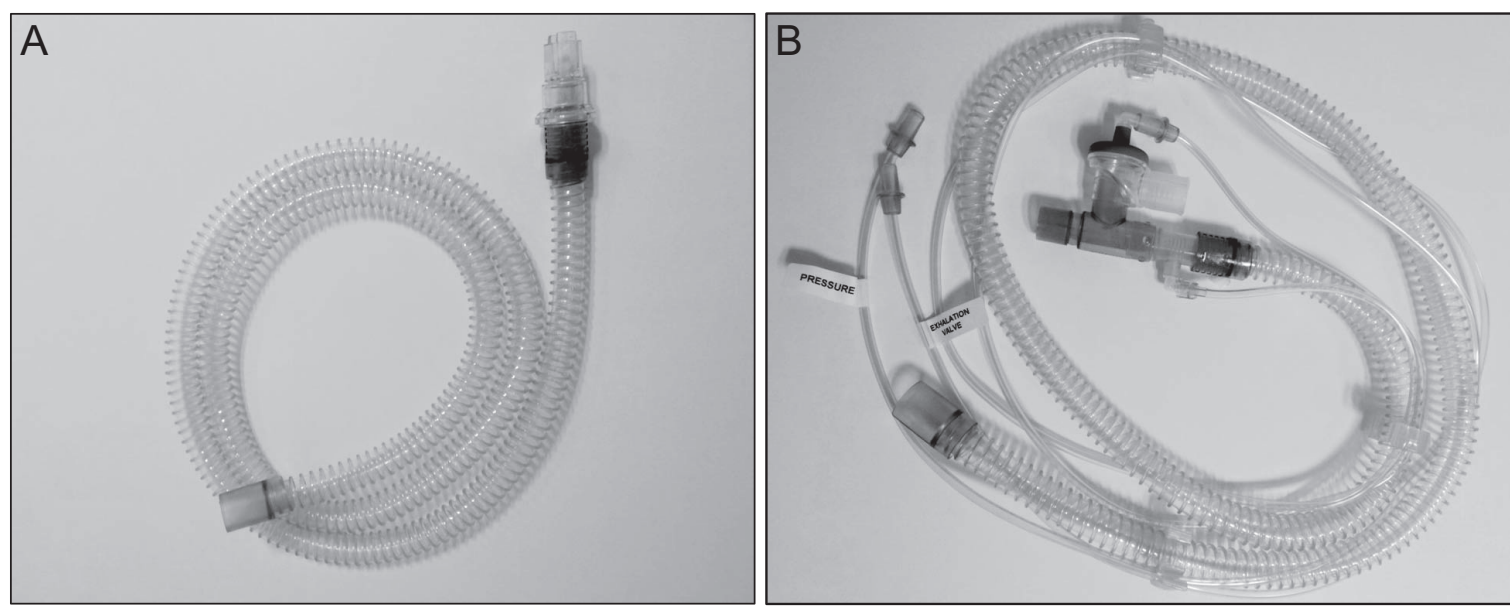

Fig. 1. Passive circuit with intentional leak (A) and active circuit with expiratory valve (B).

In our center, for all patients with ALS discharged with invasive mechanical ventilation, we suggest follow-up visits at least twice a year. During the follow-up, arterial blood gases and nocturnal pulse oximetry were measured. Moreover, the caregivers were asked to fill out a diary that reported the occurrence of respiratory infections that needed medical interventions; unplanned hospital admissions; deaths; and adverse events, which were classified into clinical events and technical events, related to invasive mechanical ventilation. Clinical events were represented by the acute occlusion of the tracheal cannula, tracheal wall instability that required variation in the tracheostomy tube model, massive tracheal bleeding, and cannula damage. Technical events were represented by urgent, unplanned technical interventions for ventilator malfunctioning, and unplanned circuit or ventilator replacements for a technical failure. The adverse event rate consisted of the number of subjects who reported at least one clinical event or technical event during the 1-y follow-up. Data related to the technical events (urgent technical interventions and replacements) were confirmed by home-care providers of all subjects involved in the study.

For all the subjects who met the inclusion criteria, we collected and analyzed arterial blood gases and data from nocturnal pulse oximetry at discharge from the hospital (T0), after 4-6 months (T1), and after 1 y (T2). All recorded data from discharge to $\mathrm{T} 2$ on respiratory infections, hospital admissions, deaths, and adverse events were collected. Our primary outcome was to compare gas exchange, adverse events, and respiratory infection rates between the passive and the active circuit groups. Our secondary outcome was to compare mortality and hospital admissions that occurred within $1 \mathrm{y}$ from the hospital discharge.

\section{Statistical Analysis}

All analyses were conducted by using SAS 9.3 (SAS Institute, Cary, North Carolina). Data were reported in the text and tables as mean \pm SD or median (interquartile range), as appropriate for continuous variables, and as the number and percentage for non-continuous variables. The variable adverse event was reported as dichotomous: category 0 , subjects who had no adverse events; and category 1 , subjects who reported at least one adverse event during the 1-y follow-up. For each variable, we used the ShapiroWilk test to evaluate the normality of the distribution and the Levene test to evaluate the homogeneity of variance. Our primary and secondary outcomes were investigated by using the $t$ test, Wilcoxon rank-sum test, Kruskal-Wallis test, chi-square test, and Fisher exact test, as appropriate. Tests were 2 -tailed, and a $P<.05$ was considered statistically significant and was adjusted by using the Bonferroni correction when appropriate. A multivariable Cox proportional hazard model was used to determine whether the type of circuit was independently related to survival and when adjusting for age and setting, with statistical significance at $P<.05$.

\section{Results}

From January 2012 to December 2014, a total of 53 subjects with ALS were started on invasive mechanical ventilation while in our center. Ten subjects were excluded from the analysis because they did not perform the follow-up in our center; therefore, 43 subjects were included in the study: 23 subjects in the passive circuit group and 20 in the active circuit group. The characteristics of the study population are shown in Table 1 . The 2 groups were homogeneous for sex, type of onset and disease phenotype, total number of follow-up visits, and dom- 


\section{Passive vs Active Circuit Ventilation in Subjects With AlS}

Table 1. Subject Characteristics

\begin{tabular}{|c|c|c|}
\hline Characteristics & $\begin{array}{l}\text { Passive Circuit } \\
\text { Group }(n=23)\end{array}$ & $\begin{array}{l}\text { Active Circuit } \\
\text { Group }(n=20)\end{array}$ \\
\hline Male/female, $n$ & $13 / 10$ & $11 / 9$ \\
\hline Age at onset, mean $\pm \mathrm{SD}$ y & $54.6 \pm 12.4$ & $63.8 \pm 8.6^{*}$ \\
\hline Age at tracheostomy, mean \pm SD y & $58.7 \pm 11.4$ & $67.8 \pm 9.2^{*}$ \\
\hline $\begin{array}{l}\text { Months from onset to tracheostomy, } \\
\text { median (IQR) }\end{array}$ & $45(28-52)$ & $40(29-49)$ \\
\hline \multicolumn{3}{|l|}{ Type of onset, $n(\%)$} \\
\hline Lower limb & $11(47.83)$ & $8(40.00)$ \\
\hline Upper limb & $6(26.09)$ & $7(35.00)$ \\
\hline Bulbar & $6(26.09)$ & $3(15.00)$ \\
\hline Generalized & $0(0)$ & $1(5.00)$ \\
\hline Respiratory & $0(0)$ & $1(5.00)$ \\
\hline \multicolumn{3}{|l|}{ Disease phenotype, $n(\%)$} \\
\hline Bulbar & $3(13.04)$ & $0(0)$ \\
\hline Classic & $17(73.91)$ & $16(80.00)$ \\
\hline Flail arm & $1(4.35)$ & $0(0)$ \\
\hline PLMN & $1(4.35)$ & $2(10.00)$ \\
\hline PUMN & $0(0)$ & $1(5.00)$ \\
\hline Pyramidal & $1(4.35)$ & $1(5.00)$ \\
\hline \multicolumn{3}{|l|}{ Follow-up, $n(\%)$} \\
\hline$<4$ & $7(30.43)$ & $7(35.00)$ \\
\hline $4-8$ & $13(56.52)$ & $6(30.00)$ \\
\hline$>8$ & $3(13.04)$ & $7(35.00)$ \\
\hline $\begin{array}{l}\text { Living situation home/protected } \\
\quad \text { facility, } n\end{array}$ & $18 / 5$ & $14 / 6$ \\
\hline $\begin{array}{l}\text { * The difference between passive and active circ } \\
\text { IQR = interquartile range } \\
\text { PLMN = pure lower motor neuron } \\
\text { PUMN = pure upper motor neuron }\end{array}$ & uit groups, $P<.01$ & \\
\hline
\end{tabular}

iciliary status. The passive circuit group significantly differed from the active circuit group for mean \pm SD age at disease onset $(54.6 \pm 12.4$ y vs $63.8 \pm 8.6 \mathrm{y}$, respectively, $P=.008$ ) and for mean $\pm \mathrm{SD}$ age at tracheostomy $(58.7 \pm 11.4$ y vs $67.8 \pm 9.2 \mathrm{y}$, respectively, $P=.007)$.

All of the subjects in the passive circuit group were receiving ventilation with Trilogy 100 (Philips Respironics, Murrysville, Pennsylvania), whereas, in the active circuit group, the ventilators used were Elisèe 150 (ResMed SA, Saint Priest, France; 7 subjects); Vivo 50 (Breas Medical AB, Mölnlycke, Sweden; 2 subjects); Puritan Bennet 560 (Covidien llc, Mansfield, Massachussetts; 4 subjects); and Monnal T50 (Air Liquide Medical Systems, Antony, France; 7 subjects). All the subjects were using ventilation in the pressure controlled mode: $78 \%$ of subjects in the passive circuit group versus $55 \%$ in the active circuit group with the addition of a target volume. During the first year, the ventilation mode remained unchanged for most of the subjects $(82.6 \%$ in the passive circuit group vs $95 \%$ in the active circuit group). The majority of the subjects were using ventilation with an $\mathrm{F}_{\mathrm{IO}_{2}}$ of $0.21(78.3 \%$ in the passive circuit group vs $75 \%$ in the active
Table 2. Ventilation Parameters and Gas Exchange at Discharge From the Hospital

\begin{tabular}{|c|c|c|c|}
\hline Parameters & $\begin{array}{l}\text { Passive Circuit } \\
\text { Group }(n=23)\end{array}$ & $\begin{array}{l}\text { Active Circuit } \\
\text { Group }(n=20)\end{array}$ & $P$ \\
\hline $\begin{array}{l}\text { Minimum pressure support, } \\
\mathrm{cm} \mathrm{H}_{2} \mathrm{O}\end{array}$ & $13(11-15)$ & $14(11-15)$ & .92 \\
\hline 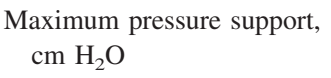 & $16(15-18)$ & $19(16-25)$ & .10 \\
\hline Pressure support, $\mathrm{cm}_{2} \mathrm{O}$ & $16(15-18)$ & $15(13-16)$ & .40 \\
\hline EPAP, $\mathrm{cm} \mathrm{H}_{2} \mathrm{O}$ & $6(5-6)$ & $6(5-6)$ & .82 \\
\hline $\mathrm{V}_{\mathrm{T}}, \mathrm{mL}$ & $500(500-550)$ & $500(500-500)$ & .30 \\
\hline Mean nocturnal $\mathrm{S}_{\mathrm{pO}_{2}} \%$ & $97(60-98)$ & $97(95-98)$ & .49 \\
\hline ODI & $0.10(0-0.40)$ & $0.30(0-0.65)$ & .33 \\
\hline Т90, \% & $0.1(0-0.1)$ & $0.1(0-0.1)$ & .53 \\
\hline $\mathrm{F}_{\mathrm{IO}_{2}}$ & $0.21(0.21-0.21)$ & $0.21(0.21-0.24)$ & .11 \\
\hline $\mathrm{P}_{\mathrm{aO}_{2}}, \mathrm{~mm} \mathrm{Hg}$ & $83(75-88)$ & $83(78-93)$ & .72 \\
\hline $\mathrm{P}_{\mathrm{aCO}_{2}}, \mathrm{~mm} \mathrm{Hg}$ & $30(26-32)$ & $30(28-34)$ & .54 \\
\hline $\mathrm{pH}$ & $7.51(7.49-7.55)$ & $7.50(7.47-7.54)$ & .45 \\
\hline $\mathrm{HCO}_{3}{ }^{-}, \mathrm{mEq} / \mathrm{L}$ & $25(23-28)$ & $24(23-28)$ & .97 \\
\hline \multicolumn{4}{|c|}{$\begin{array}{l}\text { All variables are reported as median (interquartile range). } \\
\mathrm{EPAP}=\text { expiratory positive airway pressure } \\
\mathrm{V}_{\mathrm{T}}=\text { tidal volume } \\
\mathrm{ODI}=\text { oxygen desaturation index } \\
\mathrm{T} 90=\text { percentage of time spent with } \mathrm{S}_{\mathrm{pO}_{2}}<90 \% \text { at night } \\
\mathrm{P}_{\mathrm{aO}_{2}}=\text { partial pressure of oxygen } \\
\mathrm{P}_{\mathrm{aCO}_{2}}=\text { partial pressure of carbon dioxide } \\
\mathrm{HCO}_{3}-\text { = bicarbonate }\end{array}$} \\
\hline
\end{tabular}

circuit group). The parameters used during invasive mechanical ventilation are reported in Table 2 .

The passive and active circuits were equally effective in correcting nocturnal and diurnal oxygenation, as shown in Table 2. Furthermore, only in the passive circuit group, we found a significant improvement of $\mathrm{P}_{\mathrm{aO}_{2}}$ at $\mathrm{T} 1$ and $\mathrm{T} 2$ compared with T0 (Table 3), with no change in the $\mathrm{F}_{\mathrm{IO}_{2}}$ during the same period of time.

The adverse event rate was significantly higher in the active circuit than in the passive circuit group (85\% vs $30.5 \%$ respectively, $P<.001)$. However, when dividing the adverse events into 2 categories, clinical events and technical events, only the technical events were found to be significantly more frequent in the active circuit group, as shown in Table 4. The number and distribution of clinical events related to invasive mechanical ventilation are described in e-Table 1 (see the supplementary materials at http://www.rcjournal.com). None of these events led to hospital admission or death. There was no difference between the 2 groups in terms of respiratory infection rate, hospital admissions, and deaths (Table 5). The analysis for 1-y survival did not show any differences between the 2 groups (hazard ratio $=1.11, P=.88$ ).

\section{Discussion}

To our knowledge, these were the first clinical data on the efficacy and safety of the use of a passive circuit 


\section{Passive vs Active Circuit Ventilation in Subjects With AlS}

Table 3. Arterial Blood Gases

\begin{tabular}{|c|c|c|c|c|}
\hline Parameters & T0 & $\mathrm{T} 1$ & $\mathrm{~T} 2$ & $P$ \\
\hline \multicolumn{5}{|c|}{ Passive circuit group } \\
\hline $\mathrm{F}_{\mathrm{IO}_{2}}$ & $0.21(0.21-0.21)$ & $0.21(0.21-0.21)$ & $0.21(0.21-0.21)$ & .44 \\
\hline $\mathrm{P}_{\mathrm{aO}_{2}}, \mathrm{~mm} \mathrm{Hg}$ & $83(75-88)$ & $99(88-104)$ & $96(85-105)$ & $<.001$ \\
\hline $\mathrm{P}_{\mathrm{aCO}_{2}}, \mathrm{~mm} \mathrm{Hg}$ & $30(26-32)$ & 27 (24-32) & $27(23-34)$ & .71 \\
\hline $\mathrm{pH}$ & 7.51 (7.49-7.55) & $7.52(7.49-7.55)$ & $7.54(7.50-7.57)$ & .56 \\
\hline $\mathrm{HCO}_{3}{ }^{-}, \mathrm{mEq} / \mathrm{L}$ & $25(23-28)$ & $24(22-25)$ & $23(21-27)$ & .42 \\
\hline \multicolumn{5}{|l|}{ Active circuit group } \\
\hline $\mathrm{F}_{\mathrm{IO}_{2}}$ & $0.21(0.21-0.24)$ & $0.21(0.21-0.21)$ & $0.21(0.21-0.21)$ & .68 \\
\hline $\mathrm{P}_{\mathrm{aO}_{2}}, \mathrm{~mm} \mathrm{Hg}$ & $83(78-93)$ & 97 (85-99) & 95 (88-105) & .16 \\
\hline $\mathrm{P}_{\mathrm{aCO}_{2}}, \mathrm{~mm} \mathrm{Hg}$ & $30(28-34)$ & $29(27-35)$ & $28(24-35)$ & .55 \\
\hline $\mathrm{pH}$ & $7.50(7.47-7.54)$ & $7.51(7.49-7.54)$ & $7.53(7.48-7.59)$ & .44 \\
\hline $\mathrm{HCO}_{3}{ }^{-}, \mathrm{mEq} / \mathrm{L}$ & $24(23-28)$ & $26(22-28)$ & $24(20-27)$ & .53 \\
\hline $\begin{array}{l}\text { Data of all variables are } \\
\mathrm{T} 0=\text { at discharge from } \mathrm{t} \\
\mathrm{T} 1=\text { after } 4-6 \mathrm{mo} \\
\mathrm{T} 2=\text { after } 1 \mathrm{y} \\
\mathrm{P}_{\mathrm{aO}_{2}}=\text { partial pressure o } \\
\mathrm{P}_{\mathrm{aCO}_{2}}=\text { partial pressure } \\
\mathrm{HCO}_{3}{ }^{-}=\text {bicarbonate }\end{array}$ & fuartile range). & & & \\
\hline
\end{tabular}

Table 4. The Incidence of Adverse Events due to Invasive Mechanical Ventilation

\begin{tabular}{lccc}
\hline \hline \multicolumn{1}{c}{ Adverse Event } & $\begin{array}{c}\text { Passive Circuit } \\
\text { Group }\end{array}$ & $\begin{array}{c}\text { Active Circuit } \\
\text { Group }\end{array}$ & $P$ \\
\hline Adverse event rate* & $7(30)$ & $17(85)$ & $<.001$ \\
Clinical events $\dagger$ & 6 & 5 & .93 \\
Technical events $\dagger$ & 3 & 14 & .003 \\
& & & \\
$*$ The number (percentage) of the subjects who reported at least one clinical or technical event \\
during the 1-y follow-up. \\
$\dagger$ The total number of events for each group. \\
\end{tabular}

Table 5. Acute Medical Events

\begin{tabular}{lrcr}
\hline \hline Acute Medical Event & $\begin{array}{c}\text { Passive Circuit } \\
\text { Group }\end{array}$ & $\begin{array}{c}\text { Active Circuit } \\
\text { Group }\end{array}$ & $P$ \\
\hline Acute chest infections, $n(\%)$ & & & .42 \\
0 & $7(30.43)$ & $9(45.00)$ & \\
1 & $6(26.09)$ & $6(30.00)$ & \\
$>1$ & $10(43.48)$ & $5(25.00)$ & \\
Unplanned hospital & & & .58 \\
$\quad$ admissions, $n(\%)$ & & & \\
0 & $15(65.22)$ & $10(50.00)$ & \\
1 & $5(21.74)$ & $7(35.00)$ & \\
$>1$ & $3(13.04)$ & $3(15.00)$ & \\
Deaths at 1 y, $n(\%)$ & $4(36.36)$ & $4(50.00)$ & .55 \\
Months from tracheostomy to & $17.04 \pm 10.36$ & $16.04 \pm 10.06$ & .84 \\
$\quad$ death, mean \pm SD & & & \\
\hline
\end{tabular}

during invasive mechanical ventilation in any patients. So far, the 2 different exhalation ports have been evaluated only in bench studies ${ }^{7,8}$ or in a clinical setting during non- invasive ventilation. ${ }^{7}$ Our results indicated that the passive circuit was as effective as the active circuit in eliminating carbon dioxide and in correcting gas exchange when treating subjects with ALS by using invasive mechanical ventilation and that this effectiveness was maintained over time. However, none of our subjects had chronic pulmonary disease as a comorbidity that could lead to hypercapnia. For this reason, these results cannot be extended to other patients receiving invasive ventilation for chronic hypercapnic respiratory failure. Moreover, we used expiratory positive airway pressure values higher than those suggested in the literature as the minimum required, ${ }^{9}$ and this may, in part, explain the effectiveness of $\mathrm{CO}_{2}$ washout, even when using a passive circuit. However, expiratory positive airway pressure levels were not significantly different between the 2 groups.

We found a significant improvement of $\mathrm{P}_{\mathrm{aO}_{2}}$ over time only in the passive circuit group, despite no increase in $\mathrm{F}_{\mathrm{IO}_{2}}$ and no changes in the mechanical ventilation parameters. The difference in age at disease onset and at tracheostomy could explain the improvement in gas exchange in the passive circuit group; indeed, this could promote a better response to mechanical ventilation (eg, better lung recruitment) in younger patients with less compromised ventilation/perfusion matching. Moreover, younger patients may be prone to spend more time in a sitting position, which allows a postural lung recruitment.

The incidence of chest infections, unplanned admissions for acute respiratory events, and deaths after $1 \mathrm{y}$ did not differ between the 2 groups, whereas the incidence of adverse effects was significantly higher in the active circuit group compared with the passive circuit group, particularly in terms of 


\section{Passive vs Active Circuit Ventilation in Subjects With AlS}

the number of ventilator replacements for technical failure. However, no deaths were due to adverse events.

Risk management is a key aspect to be considered in patients who are using a ventilator at home. Our definition of adverse events was in line with other studies. ${ }^{10,11}$ However, the design of our study did not allow us to establish a cause-effect relationship between these data and the type of circuit used. Nevertheless, in our clinical experience, several episodes of technical failure are due to the condensation accumulated on the membrane of the active exhalation port, so we could speculate that this might explain the occurrence of more frequent technical problems, which requires the replacement of the ventilator in the active circuit group. Unfortunately, the retrospective design of our study and of the data supplied by home-care providers did not allow us to establish whether the recorded technical problems were related to the circuit or to the ventilator. Moreover, the higher age at disease onset and at the time of tracheotomy in the active circuit group itself might have contributed to the increased incidence of complications in the active circuit group. Irrespective of the possible reasons that caused this finding, we could still assert that the use of a passive circuit in these subjects was not inferior to the active one in terms of technical and clinical complications.

Humidification effectiveness during invasive mechanical ventilation is mandatory to prevent dryness and damage to the mucosa of the respiratory tract and to avoid reduced secretion clearance. ${ }^{12-15}$ In our cohort, there were no differences in the incidence of tracheostomy tube occlusions or other acute respiratory complications. This extremely important finding indicated that, despite the presence of an intentional leak in the passive circuit, a variable loss of active humidification did not compromise the clinical safety of these subjects.

The use of a passive circuit may offer several advantages compared with the active circuit. The passive circuit is lightweight and simple to use, and has lower expiratory resistance. Furthermore, the passive circuit offers an important advantage when using the pressure controlled mode with a target volume during uncuffed open ventilation, which allows the patient with preserved bulbar function to speak during invasive mechanical ventilation. ${ }^{16}$ In fact, as shown in a recent bench study, ${ }^{17}$ during volume-targeted pressure control mode, in the presence of non-intentional leaks, the active circuit fails to maintain the target volume, which shows a clinically relevant fall in inspiratory pressure, whereas the passive circuit is able to guarantee this volume, even in cases of very high leaks.

This study had limitations. Some of these limitations arose from the study's retrospective nature. In addition, it was partially based on information obtained from the medical history collected from the subjects and caregivers and on data supplied by home-care providers, which may not have been sufficient for interpretation. The small size of our sample was, in part, due to the relatively recent introduction in Europe of passive circuits for invasive mechanical ventilation use. This could have reduced the power of the study and prevented us from stratifying the analysis to detect potential confounding variables.

\section{Conclusions}

We found that the use of the passive circuit during home invasive mechanical ventilation in the subjects with ALS was not inferior to the use of the active circuit in assuring a good correction of respiratory gas exchange and in maintaining a similar profile of safety. Moreover, the passive circuit seemed to be related to a significantly lower number of technical problems. However, these data must be confirmed in a future randomized controlled study specifically designed to compare the 2 different circuits and to possibly extend these results to other pathologies.

\section{REFERENCES}

1. Hardiman O. Management of respiratory symptoms in ALS. J Neurol 2011;258(3):359-365.

2. Oliveira AS, Pereira RD. Amyotrophic lateral sclerosis (ALS): three letters that change the people's life. For ever. Arq Neuropsiquiatr 2009;67(3A):750-782.

3. Fraticelli AT, Lellouche F, L'her E, Taillé S, Mancebo J, Brochard L. Physiological effects of different interfaces during noninvasive ventilation for acute respiratory failure. Crit Care Med 2009;37(3):939-945.

4. Carvalho MD, Swash M. Awaji diagnostic algorithm increases sensitivity of El Escorial criteria for ALS diagnosis. Amyotroph Lateral Scler 2009;10(1):53-57.

5. Brooks BR, Miller RG, Swash M, Munsat TL; World Federation of Neurology Research Group on Motor Neuron Diseases. El Escorial revisited: revised criteria for the diagnosis of amyotrophic lateral sclerosis. Amyotroph Lateral Scler Other Motor Neuron Disord 2000; 1(5):293-299.

6. World Federation of Neurology Research Group on Neuromuscular Diseases Subcommittee on Motor Neuron Disease. Airlie House guidelines. Therapeutic trials in amyotrophic lateral sclerosis. Airlie House 'Therapeutic Trials in ALS' Workshop Contributors. J Neurol Sci 1995;129(Suppl):1-10.

7. Lofaso F, Aslanian P, Richard JC, Isabey D, Hang T, Corriger E, et al. Expiratory valves used for home devices: experimental and clinical comparison. Eur Respir J 1998;11(6):1382-1388.

8. Sogo $\mathrm{A}$, Montanyà J, Monsó $\mathrm{E}$, Blanch L, Pomares X, Lujàn M. Effect of dynamic random leaks on the monitoring accuracy of home mechanical ventilators: a bench study. BMC Pulm Med 2013;13:75.

9. Lofaso F, Brochard L, Hang T, Lorino H, Harf A, Isabey D. Home versus intensive care pressure support devices. Experimental and clinical comparison. Am J Respir Crit Care Med 1996;153(5):1591-1599.

10. Simonds AK. Risk management of the home ventilator dependent patient. Thorax 2006;61(5):369-371.

11. Chatwin M, Heather S, Hanak A, Polkey MI, Simonds AK. Analysis of home support and ventilator malfunction in 1,211 ventilator-dependent patients. Eur Respir J 2010;35(2):310-316.

12. American Association for Respirtory Care, Restrepo RD, Walsh BK. Humidification during invasive and noninvasive mechanical ventilation: 2012. Respir Care 2012;57(5):782-788. 


\section{Passive vs Active Circuit Ventilation in Subjects With Als}

13. Cinnella G, Giardina C, Fischetti A, Lecce G, Fiore MG, Serio G, et al. Airways humidification during mechanical ventilation. Effects on tracheobronchial ciliated cells morphology. Minerva Anestesiol 2005;71(10):585-593.

14. Al Ashry HS, Modrykamien AM. Humidification during mechanical ventilation in the adult patient. Biomed Res Int 2014;2014: 715434

15. Cerpa F, Cáceres D, Romero-Dapueto C, Giugliano-Jaramillo C, Pérez R, Budini $\mathrm{H}$, et al. Humidification on ventilated subjects:
Heated humidifications or heat and moisture exchangers? Open Respir Med J 2015;9:104-111.

16. Bach JR, Gonçalves MR, Rodriguez PL, Saporito L, Soares L. Cuff deflation: rehabilitation in critical care. Am J Phys Med Rehabil 2014;93(8):719-723.

17. Carlucci A, Schreiber A, Mattei A, Malovini A, Bellinati J, Ceriana $\mathrm{P}$, Gregoretti C. The configuration of bi-level ventilator circuits may affect compensation for non-intentional leaks during volume-targeted ventilation. Intensive Care Med 2013;39(1):59-65. 